\title{
An empirical assessment of the merger between Iberia, Clickair and Vueling
}

\author{
Xavier Fageda Sanjuan \\ University of Barcelona and GIM-IREA
}

\begin{abstract}
In this paper, I apply a difference-in-difference estimator to examine the impact of the merger between Iberia, Clickair and Vueling on route flight frequency, which is considered to be the main attribute of quality in the sector. Controlling for different indicators of competition and several route attributes, I show that the merger has implied a decrease in route flight frequency but the magnitude of this effect is modest. A plausible explanation of my result is a more collusive behavior of airlines offering flights in the routes affected by the merger.
\end{abstract}

Keywords: airlines, merger, competition, flight frequency, difference-in-difference estimator.

JEL classification: L93, D43, LA.

\section{Resumen}

En este artículo se aplica un estimador de diferencias en diferencias para examinar el impacto de la fusión entre Iberia, Clickair y Vueling en la frecuencia de vuelos a nivel de ruta, que está considerado como el principal atributo de calidad en el sector. Controlando por diferentes indicadores de competencia y varios atributos a nivel de ruta, muestro que la fusión ha supuesto una disminución de la frecuencia de la ruta de vuelo, pero la magnitud de este efecto es modesto. Una explicación plausible de mi resultado es un comportamiento más colusivo de las compañías aéreas que ofrecen vuelos en las rutas afectadas por la fusión.

Palabras clave: aerolíneas, fusiones, competencia, frecuencia de vuelos, estimador de diferencias en diferencias.

Clasificación JEL: L93, D43, L4.

\section{Introduction}

Several events may have influenced the evolution of competition in the Spanish airline market in the last years. The increase in the capacity of the largest airports, particularly Madrid and Barcelona, has diluted the negative effect related to what is considered the main barrier to entry in the sector, the scarcity of slots. Furthermore, the increasing presence of leading low-cost airlines like Ryanair or Easyjet have spur price rivalry ${ }^{1}$. Note also that some steps have been done towards a liberalization of traffic between Spain and non-European Union countries being the open skies

${ }^{1}$ See FAGEDA and FERNÁNDEZ VILLADANGOS (2009) for an empirical examination of the effect of these two events on prices charged by airlines in a set of domestic routes. 
agreement between United States and the European Union the most clear and important example.

However, the Spanish airline market has also been affected by a consolidation process with likely negative consequences in terms of competition. In this regard, the former Spanish flag carrier, Iberia, has been involved in two recent mergers. Iberia became the main shareholder of Vueling after the merger of this airline with its lowcost-subsidiary, Clickair. Additionally, Iberia recently merged with British Airways. Given that airlines usually operate on an international basis given the nature of its activity, decisions about mergers usually are made by the European Commission and not by national competition authorities.

The merger between Iberia and British Airways has not had an impact on competition, at least in terms of traffic in non-stop routes, in the Spanish airline market ${ }^{2}$. This merger was approved in November 2008 by the European Commission (case no. COMP/M.5747-Iberia/ British Airways) and the integration was done in January 2011 although both firms still operate under different brands. Note that both airlines were already operating like a single airline in terms of their route choices before the merger as they were closely integrated within the Oneworld alliance. In fact, both airlines were just offering services simultaneously before the merger in the routes that link Madrid and Barcelona with London-Heathrow.

A descriptive analysis for these two routes reveals the following facts using flight frequency data of RDC aviation. In the comparison of the supply in a period before the merger was completed (years 2008 and 2009) and after the merger (2012 and 2013), I may check a decrease in frequencies in the route Madrid-London of just 3 per cent and a strong stability in the share of the two airlines offering services there; 60 per cent of total flights are operated by Iberia and 40 per cent by British Airways in both periods. In the route Barcelona-London, the decrease in total route frequencies between the two periods is about 23 per cent. In the period before the merger, the share of Iberia was about 40 per cent while the share of British Airways was about 60 per cent. In the period after the merger, British Airways is the only airline that offers services in this route and it has increased frequencies to partially compensate the withdrawal of Iberia. The withdrawal of Iberia on the route Barcelona-London must be understood within the more general strategy of Iberia of concentrate all its flights in its hub, Madrid. From Barcelona airport, Iberia currently only offers flights to the route that link with Madrid. Thus, the influence of the merger in the supply of flights in the route Barcelona-London is not relevant, as it is not the case in the route Madrid-London.

The impact of the merger between Iberia, Clickair and Vueling deserves much more attention in terms of the analysis of their effects on the supply of flights in nonstop routes departing from Spanish airports. Indeed, a high number of routes were

2 The impact on connectging traffic may have been stronger but the analysis of competition in routes with different stops would require working with demand data for the true origin and destination of passengers. Unfortunately, I do not have such data to undertake this analysis. 
simultaneously operated by Iberia and Vueling, or Clickair and Vueling before the merger was approved. Furthermore, price rivalry between Clickair and Vueling was intense in such a period (Fageda et al., 2012). It may also be expected that frequency competition was also strong in the years previous to the merger.

Mergers may have a detrimental effect on the welfare of passengers in two different but interrelated dimensions; prices and flight frequency. Flight frequency is considered the main attribute of quality in the airline market because it determines the schedule delay cost which is the difference between the actual and desired time of departure (Bilotkach et al., 2010). Note also that flight frequency is a strong determinant of prices as it has an influence on the fixed costs of airlines and load factors of the planes.

In this paper, I examine the impact on flight frequencies of the merger between Iberia, Clickair and Vueling. I run several regressions controlling for different indicators of competition taking advantage of a rich dataset that include domestic and international routes. The econometric evaluation of the merger is done through the difference-in-difference method which is a method widely used in the analysis of mergers. Results of my analysis may be useful to assess the effects of such merger for passengers and hence they may help motivate future decisions of the competition authorities on mergers in the Spanish air transport market.

Here, it is important to remark that several studies have examined the impact of mergers on prices (i.e. Kim and Singal, 1993; Morrison, 1996; Peters, 2006; Zhang and Round, 2009; Dobson and Piga, 2013) but there is scarce evidence about the impact of mergers on frequencies. Only the works of Bilotkach (2011), Borenstein (1990), Fageda and Perdiguero (2014), Richard (2003) and Werden et al. (1991) have provided empirical analysis of the mergers on frequencies.

The remaining of this paper is organized as follows. In the second section, I provide some details and related references of the merger examined. Then, I specify the empirical model and state my expectations for each explanatory variable. The following section reports the regression results. The last section contains the concluding remarks.

\section{The merger between Iberia, Clickair and Vueling}

In 2006 Iberia initiated a new business plan that led to the concentration of its operations at its main hub, the airport of Madrid-Barajas. A further measure in this plan was to create a new low-cost airline, Clickair, with an operating base located in the airport of Barcelona-El Prat. Iberia had a 20 per cent stake in Clickair and controlled 80 per cent of its economic rights. Using Iberia's slots and resources, Clickair soon acquired the largest market share at Barcelona airport. Note that Iberia did not have formally a majority holding in the capital of Clickair so that it is doubtful whether the transfer of slots was lawful. 
One of the most probable motives for the creation of Clickair was to compete with another Spanish low-cost airline, Vueling, which had become a serious competitor to Iberia in the Spanish domestic market. Indeed, Fageda et al. (2012) shows that while operating as Iberia, the former Spanish flag carrier was restricted in its attempts to charge lower prices than those of its rivals. As Clickair, however, Iberia was able to charge very low prices. Data in this study show that the head-to-head competition between Clickair and Vueling led to a substantial reduction in prices on the routes in which both companies operated. In fact, the financial situation of the latter airline seriously deteriorated in this period to the point that was near bankruptcy in 2008 .

In July 2008, Iberia, Clickair and Vueling agreed a two-step merger deal: first, Clickair was taken over by Vueling (with Clickair ceasing to operate) and, second, Iberia became the leading shareholder in the new firm (now called Vueling). Iberia thus obtained 45.8 per cent of the shares, while the second largest shareholder was Nefinsa with 4.15 per cent of the shares. Nefinsa is the owner of Air Nostrum, a regional airline that has a franchisee contract with Iberia. The remaining 50 per cent of the capital was owned by shareholders (investment funds and individual investors) with holdings well below 1 per cent ${ }^{3}$. Thus, Iberia effectively controls the board of directors of the new Vueling. In January 2009, the European Commission agreed to the merger between Iberia, Clickair and Vueling on the condition that certain slots on given routes were transferred to other airlines (case no. COMP/M-5364-Iberia/ Vueling/Clickair). The merger was completed in July 2009.

Iberia does not had a majority holding in the capital of Vueling just after the merger, since it held less than 50 per cent of shares. However, the integration of the two companies' respective operations was quite clear (recall that all other investors were minority shareholders in Vueling's capital). Since the merger was made effective, most of Vueling's flights are offered under code-share agreements with Iberia; yet, they do not operate simultaneously on any route except Madrid-Barcelona (which is one of the densest routes in the world). Furthermore, since the merger came into effect, they have shared the same frequent flyer program.

Fageda et al. (2012) show that the new subsidiary of Iberia was able to increase prices substantially after the merger was complete. Thus, the war prices between Clickair and Vueling was followed by a substantial increase of prices once Vueling was integrated in Iberia's group. It is not unreasonable to state that Iberia was following a predatory behaviour to force the exit of a serious rival. Given that predatory behaviour is considered to be an anti-competitive practice, it would appear that a merger appraisal should also include the evaluation of predatory practices by the firm acquiring its rival.

Fageda and Perdiguero (2014) provide an empirical examination of the merger between Iberia, Clickair and Vueling that is closely related with this study. They examine the impact on prices and frequencies of this merger. They find a modest

${ }^{3}$ Recently, IAG (which it is the financial holding controlling Iberia and British Airways) took the remaining capital of Vueling. 
effect on prices and frequencies when considering the affected routes in general terms. However, their results show that the impact on prices is high when the routes affected are those where Iberia and Vueling were simultaneously operating before the merger and the impact on frequencies is high when the routes affected are those where Iberia and Clickair were simultaneously operating before the merger. They argue that the behavior of the airlines following the merger may be related to the different passenger types who are the predominant users of the routes affected by the merger. It would appear that the proportion of leisure travelers (price sensitive and less time sensitive) is higher on routes where the two low-cost airlines previously operated. By contrast, the proportion of business passengers (more time sensitive and less price sensitive than leisure passengers) appears to be higher on routes on which the network carrier and one of the low-cost carriers previously operated.

This paper conducts a similar analysis to that of Fageda and Perdiguero (2014) but it takes advantage of a richer dataset. Hence, I can provide a more rigorous test of the impact of the considered merger on flight frequencies. The study of Fageda and Perdiguero (2014) was based on 73 domestic routes and data of flight frequencies were taken for a sample week. The period analyzed was from the summer of 2001 to the summer of 2011, considering the summer of 2009 the period in which the merger was binding. Routes affected by the merger were considered to be those where Vueling was competing with Clickair or Iberia in at least one season (either summer or winter) of the previous years to the merger. Note also that the levels of competition were just approximated by the concentration index.

The empirical analysis in this study uses 189 routes including domestic and international routes. Hence, I can analyze whether the impact of the merger has been stronger in domestic or international routes and I can control for new variables like competition from secondary airports (which mainly affects international routes). Note also that information for flight frequencies refer to all year and not just a sample week.

Additionally, I make a stricter separation between the periods before and after the merger. To guarantee the symmetry between the two periods, I consider data for two years before the merger was approved (years 2006 and 2007) and two years after the merger was completed (years 2010 and 2011). Hence, I drop from the analysis two years (years 2008 and 2009) in which the airlines involved in the merger were likely not competing intensively. Alternatively, it could be also interesting to examine the behavior of the airlines when they were aware of the merger but still was not made effective. However, my focus here is on the impact of the mergers on passengers (in terms of flight frequency) and not on the behavior of the airlines in different scenarios.

I also make a stricter separation between the routes affected or not affected by the merger. I consider that the routes affected by the merger are those routes in which Vueling was competing with Clickair or Iberia both in 2006 and 2007 and the routes not affected by the merger are considered to be those where Vueling was not competing with any of the other airlines neither in 2006 nor 2007. So, I 
drop those routes where Vueling was competing with any of the other airlines in 2006 or 2007 because these routes cannot be strictly classified as routes affected by (or not) competition between the airlines involved later in the merger. Concerning the routes affected by the merger, I can examine the impact of the merger in two clearly different scenarios: 1) In the period previous to the negotiation of merger, competition between the airlines involved in the operation was intense in the routes in which they were offering simultaneously services, 2) in the period after the merger was complete, only one of the airlines involved in the merger (either Vueling or Iberia) was offering services in the same set of routes ${ }^{4}$.

Note also that I add other variables that may approximate the levels of competition in the route like the share of low-cost airlines or the share of the merged airlines in the route. The main limitation of this study in relation to that of Fageda and Perdiguero (2014) is I do not have available information for prices.

Overall, I have been able to collect complete data for 189 routes for the years 2006, 2007, 2010 and 2011 so that my sample contains 756 observations. The routes considered have Barcelona, Ibiza, Madrid or Sevilla as origin airports. The main operating base of both Clickair and Vueling was Barcelona but Vueling also had a relevant presence in Madrid, Ibiza and Sevilla. The destination airports are any airport located in the European Union. In this regard, I exclude intercontinental flights because neither Clickair nor Vueling offered flights to non-European destinations in the period previous to the merger. Among the 189 routes, 33 are affected by the merger (15 depart from Barcelona, 14 from Madrid, 2 from Ibiza and 2 from Sevilla; 19 link domestic destinations and 14 international destinations).

\section{The empirical model}

In this section, I implement a multivariate analysis to identify the impact of the considered merger on routes flight frequencies. I use similar control variables to those employed in other empirical studies that estimate the determinants of frequencies on air routes (see, for example, Schipper et al., 2002; Richard, 2003; Pai, 2010; Calzada and Fageda, 2012; Bilotkach et al., 2010, 2013; Brueckner and Luo, 2013; Zou and Hansen, 2014). The equation to estimate for route $\mathrm{k}$ at time $\mathrm{t}$ (Frequency) takes the following form:

$$
\begin{aligned}
& \text { Frequency }_{\mathrm{kt}}=\beta_{0}+\beta_{1} \text { Distance }_{\mathrm{k}}+\beta_{2} \text { Population }_{\mathrm{kt}}+\beta_{3} \text { Income_per_capita } \\
& +\beta_{\mathrm{kt}}+ \\
& +\beta_{4} \text { Ds }^{\text {econdary }}{ }_{\mathrm{kt}}+\beta_{5} D^{\text {tourism }}+\beta_{6} D^{\text {international }}{ }_{\mathrm{k}}+\beta_{7} \mathrm{D}^{\mathrm{BCN}}+\beta_{\mathrm{k}} \mathrm{D}_{\mathrm{k}}^{\mathrm{IBZ}}+\beta_{9} \mathrm{D}_{\mathrm{k}}^{\mathrm{SVQ}}+ \\
& +\beta_{10} \mathrm{D}_{\mathrm{k}}^{\text {merger_year }}+\beta_{11} \mathrm{D}_{\mathrm{t}}^{\text {merger_routes }}+\beta_{12} \text { Diff-in-Diff }{ }_{k t}+\beta_{13} \text { Competition }_{k t}+\mathrm{e}_{\mathrm{kt}}
\end{aligned}
$$

\footnotetext{
4 The exception is the route Madrid-Barcelona where both Vueling and Iberia are offering services although most of flights of Iberia are operated as a shuttle air service.
} 
In this equation, the dependent variable is the total number of annual flights offered by airlines on route $\mathrm{k}$ in year $\mathrm{t}$. As explanatory variables, I include variables that measure the population and per capita income of the destination in order to control for demand. I expect airlines to offer higher frequencies on routes that link richer and more populous cities. I also take into account the influence of the route's distance, calculated as the number of kilometers flown to link the route's endpoints. Airlines may prefer to use smaller planes at higher frequencies on short-haul routes. Thus, I would expect a negative relationship between distance and frequency

I also consider a dummy variable that takes a value of one for routes and periods in which air services are offered simultaneously from two origin airports (i.e., Barcelona and Girona, Barcelona and Reus) to the same destination. For example, Ryanair may be offering flights to Amsterdam from Girona and airlines like Vueling or Transavia may be also offering flights to the same destination from Barcelona. Demand in those routes could be higher than predicted by the other explanatory variables of my model so the coefficient associated to this variable is expected to be positive. Indeed, city-pair markets that are covered by multiple airports are usually dense markets.

I also include a dummy variable that distinguish between domestic and international routes and another that identify tourist routes. By tourist routes, I mean routes that have a destination airport located in Balearic islands, Canary islands, Sicily, Sardinia, Corsica, Malaga and Alicante as it has been considered in other previous studies (Fageda and Flores-Fillol, 2012a, 2012b). I may expect that frequencies are higher in domestic routes due to higher demand, while frequencies should be lower in tourist routes as the proportion of leisure passengers may be higher in these routes. Furthermore, I include dummy variables for the different origin airports taking Madrid as the reference case. Given that Madrid is a hub a network airline, I expect a negative sign in the coefficient associate to these dummy variables due to the higher demand derived from connecting traffic in Madrid airport.

To analyze the effect that the merger has had on frequencies, I use a differencein-difference estimator. The variable $\mathrm{D}^{\text {merger_year }}$ is a dummy variable that takes the value 1 for all routes in the periods after the merger and 0 otherwise. This variable reflects the change in frequencies before and after the merger on all the routes. The variable $\mathrm{D}^{\text {merger_routes }}$ is a dummy variable that takes the value 1 for all periods of time only on those specific routes affected by the merger and 0 otherwise. I understand routes affected by the merger as being those on which Vueling was offering services simultaneously with Clickair or Iberia in the years previous to the merger (2006 and 2007). This variable reflects the frequencies offered on those routes affected by the merger in relation to those that remain unaffected. The variable Diff-in-Diff is constructed through the interaction between $\mathrm{D}^{\text {merger_year }}$ and $\mathrm{D}^{\text {merger_routes }}$. Hence, this variable is a dummy variable that takes the value 1 only in the periods after the merger and only for those routes affected by the merger, and 0 otherwise. The coefficient accompanying this variable is the difference-in-difference estimator. If the coefficient is negative and significant then the merger led to a reduction in frequencies, while if the coefficient is positive and significant then it led to an increase in frequencies. 
I include different variables that seek to capture competition at the route level ${ }^{5}$. In a first set of regressions I consider the route concentration, measured using the Herfindahl-Hirschman index, in terms of flight frequencies. The expected sign of the coefficient associated with route concentration is negative given that airlines compete in frequencies. In a second set of regressions, I consider the route share of the airlines involved in the merger and the share of low-cost airlines on the route. Shares for both variables are calculated in terms of frequencies. The expected sign of the coefficient associated with the share of the airlines involved in the merger is negative because a higher share of these airlines may imply softer route competition.

The expected sign of the variable for the share of low-cost competitors is not clear a priori. On the one hand, a higher share of low-cost airlines may imply stronger competition on the route but, on the other hand, low-cost airlines may offer lower frequencies than network airlines as they may be more interested in capturing leisure passengers. In this regard, Goolsbee and Syverson (2008) examine the responses of incumbent US airlines to the threat of entry of Southwest using a sample of US routes. They find that incumbents reduce prices when Southwest threatens a route but these fare cuts are not accompanied by an increase in frequencies or seats. Another study that examines the impact of low-cost carriers on frequencies is that of Bettini and Oliveira (2008). They analyze the determinants of major carrier's capacity in routes connecting the 30 biggest Brazilian airports, including as explanatory variables a dummy for those routes in which Gol is offering flights. They found positive effects of low-cost entry on major carrier's capacity.

Airline frequency data at the route level have been obtained from RDC aviation (Capstats statistics), while route distance data are taken from the Official Airline Guide (OAG). Population and income per capita data refer to the NUTS 3 regions ("provincias") and have been provided by Cambridge Econometrics (European Regional Database publication). Note I use an explanatory variable that consider the share of low-cost airlines in the route. Table 1 provides a list of low-cost airlines that offer services in routes of our sample in at least one of the years of the considered period.

TABLE 1

\section{LIST OF LOW-COST AIRLINES OFFERING AIR SERVICES IN ROUTES OF OUR SAMPLE}

Air One, Air Berlin, Alpi Eagles, Condor, easyjet, Germanwings, Hapagfly, LTU, Monarch, MyAir, MyTravelLite, NIKI, Norwegian, Ryanair, SkyEurope, Smart Wings, Sterling, Thomson, Transavia, Virgin Express, Volare, Wind Jet, Wizzair

${ }^{5}$ It could be argued that concentration variables may be simultaneously determined with the number of total flights offered in the route. Any possible endogeneity bias could affect the magnitude and sign of the coefficients for these variables but is should not affect the difference-in-difference estimator. This being said, the aim of this paper is to examine the impact of the merger controlling for the intensity of competition and not to examine the impact of competition on frequencies. Note that it is hard to find good instruments for the concentration variable as the lags of these variables are strongly correlated with the contemporaneous variable. 


\section{Estimation and results}

I perform the estimation using three different techniques as a robustness check; the ordinary least squares (OLS), the route random effects and the route fixed effects. The ordinary least squares do not allow considering unobserved route heterogeneity but it is not conditioned by some inconsistency problems that may affect the other estimators.

The use of random or fixed effects allows us to consider unobserved route heterogeneity. An advantage of the fixed effects model is that it allows us to control for any omitted variables that correlate with the variables of interest and which do not change over time. A shortcoming of the fixed effects model is that the effect of timeinvariant variables cannot be identified. Note also that the fixed effects estimator may not be consistent when the number of time periods is small as it is my case here. The random effects model has the advantage that it may capture both the between and the within variation of the data but a disadvantage of the random effects model is related with the potential bias derived from the correlation between the explanatory variables and the random effects.

Table 2 shows the descriptive statistics of the variables used in the empirical analysis, while Table 3 shows the correlation matrix. All the variables show sufficient variability to provide robust estimations and none of the explanatory variables is so correlated to create a multicollinearity problem.

Table 4 shows the test for mean differences for the most relevant variables in our analysis in the period before and after the merger; flight frequency and competition variables. Regarding the routes affected by the merger, the descriptive statistics suggest a modest increase in concentration while the share of low-cost

TABLE 2

DESCRIPTIVE STATISTICS OF THE VARIABLES USED IN THE EMPIRICAL ANALYSIS

\begin{tabular}{|l|c|c|}
\hline & Mean & Standard deviation \\
\hline Frequencies & 1485.37 & 2097.22 \\
\hline Distance & 1160.58 & 582.9 \\
\hline Population & 1889.80 & 2336.65 \\
\hline Income per capita & 28.51 & 14.28 \\
\hline $\mathrm{D}^{\text {secondary }}$ & 0.13 & 0.34 \\
\hline $\mathrm{D}^{\text {tourism }}$ & 0.18 & 0.38 \\
\hline $\mathrm{D}^{\text {international }}$ & 0.65 & 0.47 \\
\hline HHI & 0.66 & 0.26 \\
\hline Share_lowcost & 0.26 & 0.37 \\
\hline Share_merged_airline & 0.40 & 0.37 \\
\hline
\end{tabular}




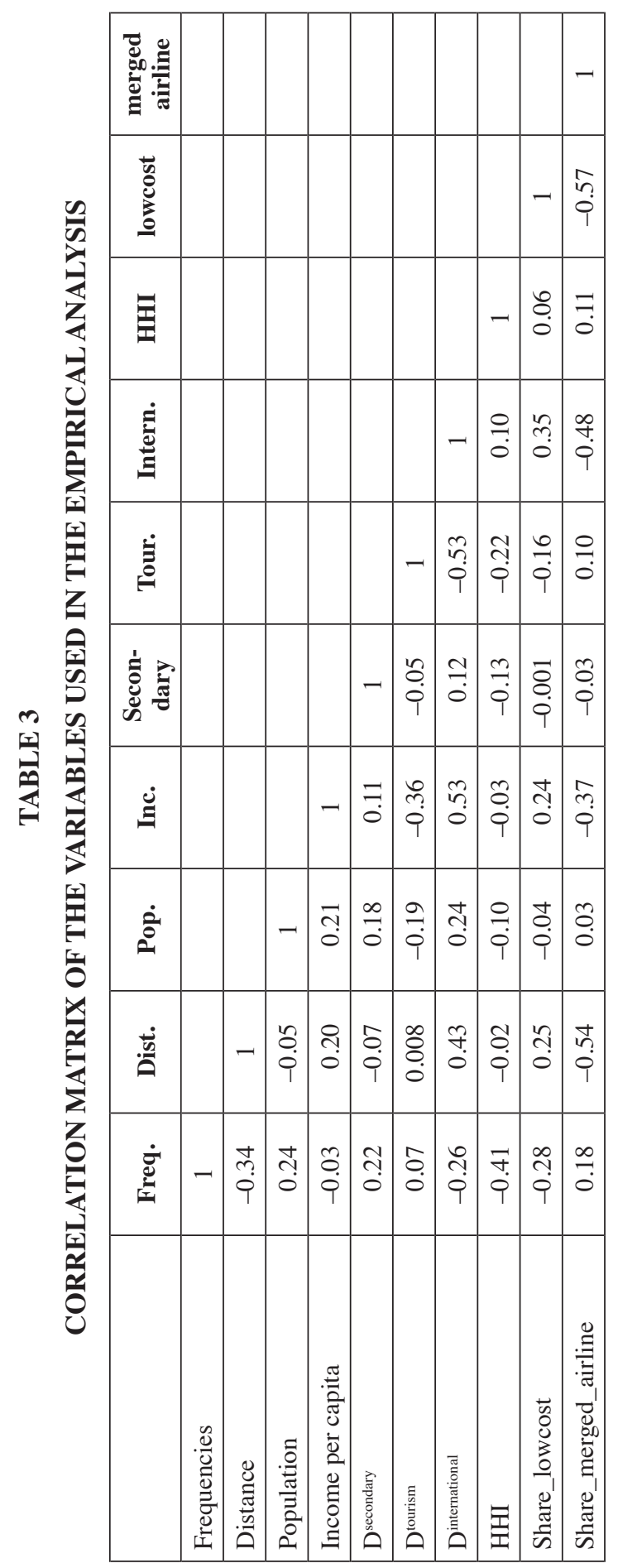




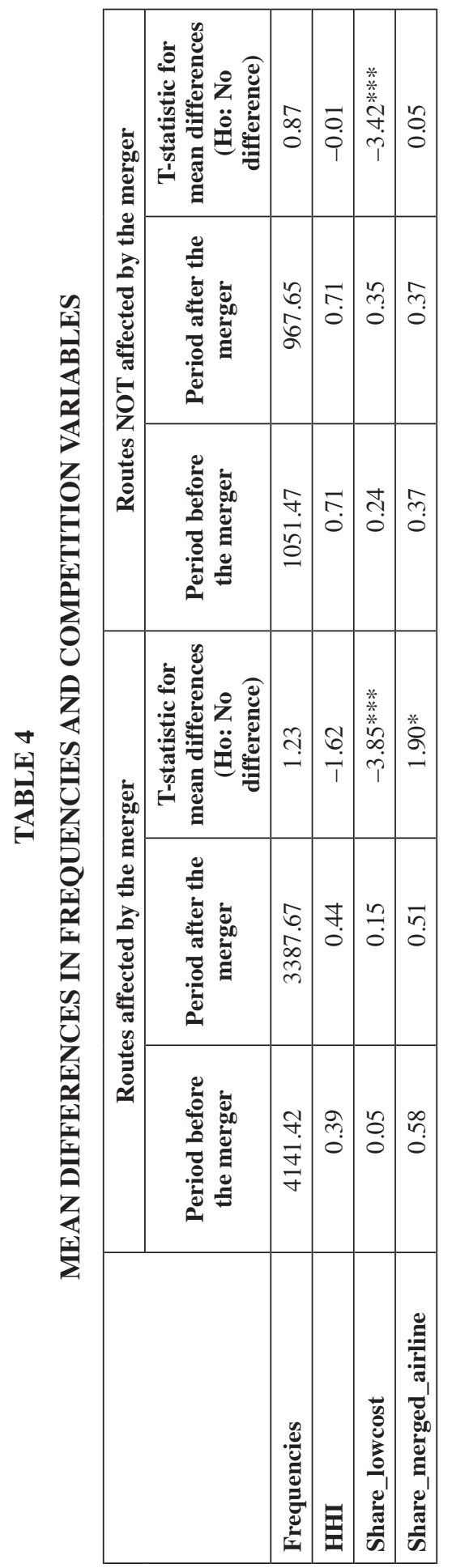


airlines has increased and the share of the airlines involved in the merger has been reduced. Therefore, data do not show a clear worsening of the competition on the routes affected by the merger. However, the decrease in frequencies is substantial. Concerning the routes not affected by the merger, there is a high stability in the mean values for all the considered variables. The only exception has to do with the share of low-cost airlines that has significantly increased in the period after the merger.

Another interesting fact from Table 4 is the strong differences in the mean values for the two periods regarding routes affected and not affected by the merger. In this regard, routes affected by the merger are denser because mean frequencies are higher. Furthermore, the levels of concentration in these routes are lower but the share of low-cost airlines is also lower.

Table 5 shows the results of estimates of the frequency equation when using all sample and variables. The overall explanatory power of the model is reasonable high when the estimation is made using ordinary least squares and random effects, while it is much lower when using the fixed effects estimation. Recall that the fixed effects model does not identify variables that are time-invariant like distance or the dummy for international routes. In this regard, the Hausman test takes a value of 18.31 and we are not able to accept the null hypothesis that differences in coefficients are not systematic. Thus, the random effects model is more informative but the fixed effects model is more reliable.

The sign of the coefficients estimated for the variables of distance, population and income per capita have the expected signs and are statistically significant when using the ordinary least squares and random effects methods, while only the variable of income per capita works as expected in the estimation that uses fixed effects (the variable of distance cannot be identified).

The coefficient associated with the dummy variable for routes in which air services are offered from secondary airports is positive in all regressions but it is only statistically significant in the regression that uses ordinary least squares. While demand in these routes may be higher than predicted by the other explanatory variables, its statistical significance is conditioned upon the estimation method used.

The coefficient of the dummy variable for tourist routes is not significant in any regression so that we do not find a differential effect for tourist routes in the frequency choices of airlines. On the contrary, the coefficient of the dummy variable for international routes is negative and statistically significant in all regressions. Hence, it seems that demand is higher in domestic routes even after controlling for other demand shifters. As expected, the coefficients of the dummy variables for the origin airports are negative and statistically significant in the regressions where they can be identified.

Regarding competition variables, the coefficient of the concentration variable is negative and statistically significant in all regressions as expected. In a similar vein, the coefficient of the dummy variable for the share of the airlines involved in the merger is also negative and statistically significant in all regressions. On the contrary, 


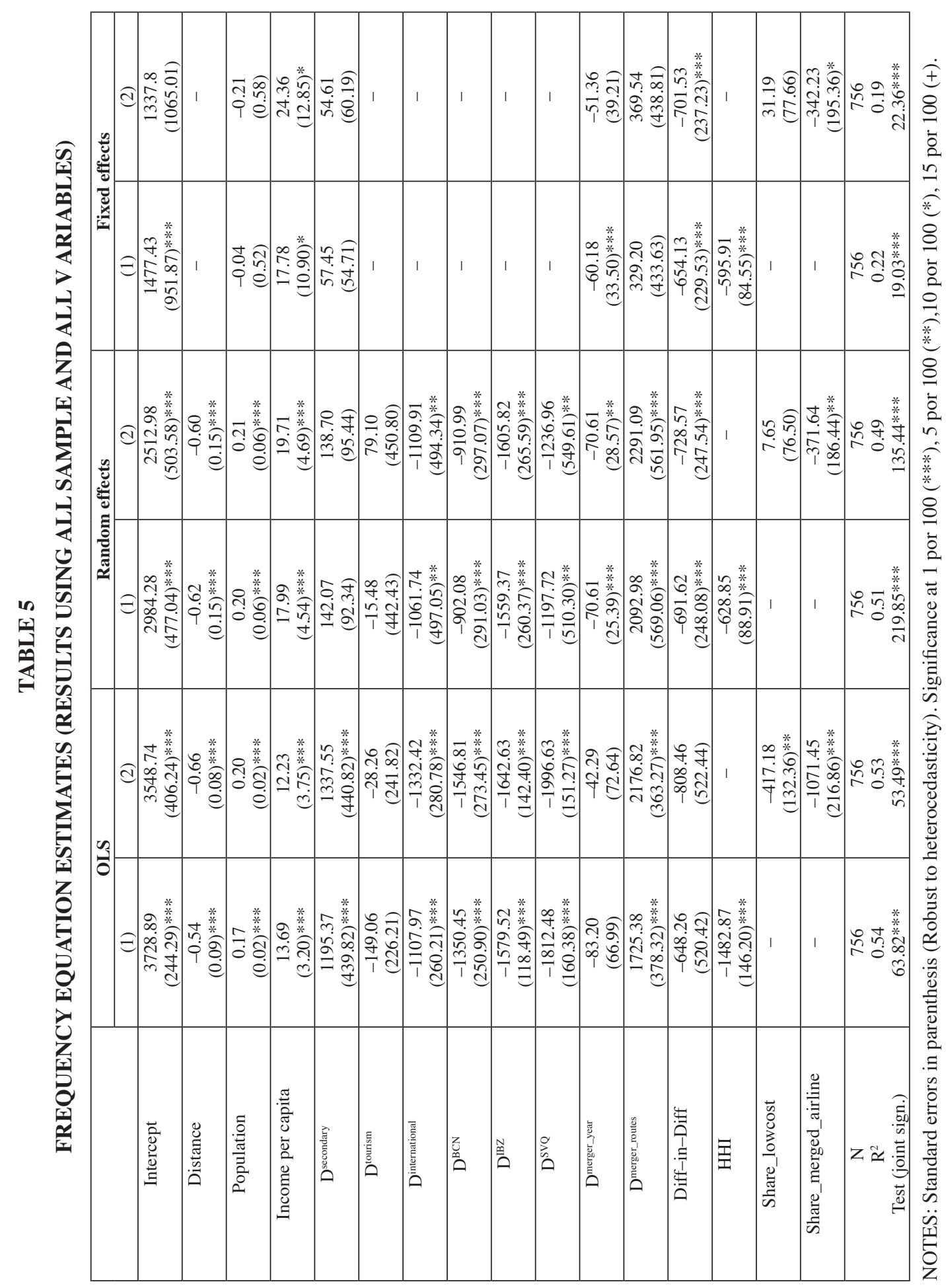


results for the variable of the share of low-cost airlines are mixed. Its coefficient is negative and statistically significant in the regression that uses ordinary least squares but it is positive and not statistically significant in the regression that uses random and fixed effects. Thus, no clear conclusions can be reached regarding this variable.

The coefficient of the dummy variable for the period after the merger is negative in all regressions although it is not statistically significant when the estimation is made using the ordinary least squares. Note that the economic situation was worse in the period after the merger so that this explains the negative sign of this coefficient. In this regard, the impact of the crisis should be similar in routes affected by the merger and routes not affected by the merger. Hence, my test about the impact of the merger on route frequencies should not be conditioned by the economic situation of the country after the merger. The effect of the economic crisis only could play a role when I make the comparison between domestic and international routes as long as domestic routes could be more negatively affected by the crisis (see below).

The coefficient of the dummy variable for routes affected by the merger is positive in all regressions although it is not statistically significant when using the fixed effects method. This result is similar to what I found in the descriptive statistics analysis developed above. Indeed, routes affected by the merger seems to be denser than other routes even when controlling for other control factors that may explain route frequencies.

The main variable of my analysis is the variable that identity the differencein-difference estimation which is the result of the interaction between the dummy variable for the period after the merger and the dummy variable for routes affected by the merger. The coefficient associated to this interaction variable is negative in all regressions. It is not statistically significant when using the ordinary least squares and it is statistically significant at the 1 per cent level when accounting for the panel nature of my date (i.e. regressions with random and fixed effects).

Table 6 shows the results of estimates of the frequency equation for different subsamples. Here I only report results for the difference-in-difference estimator as it is the main focus of the analysis. First, I consider routes that just depart from Madrid or Barcelona airport (I do not have enough observations to make specific regressions for routes departing just from Ibiza or Valencia). Then, I consider just domestic or international routes. The difference-in-difference estimator is negative in all regressions for all subsamples. In the case of routes that have Madrid airport, the coefficient is statistically significant at the 10 per cent level in all regressions. In routes departing from Barcelona airport, the coefficient of the variable is generally statistically significant at the 5 per cent or 1 per cent level. Regarding domestic routes, the interaction variable is statistically significant in all regressions at the 5 per cent level. When I focus the attention on international routes, the difference-in-difference estimator is not statistically significant when I use the ordinary least squares and it is statistically significant at the 1 per cent level when I use fixed or random effects.

Table 7 shows the elasticities obtained from the estimates for the difference-indifference variable. The magnitude of the estimated elasticities moves generally 


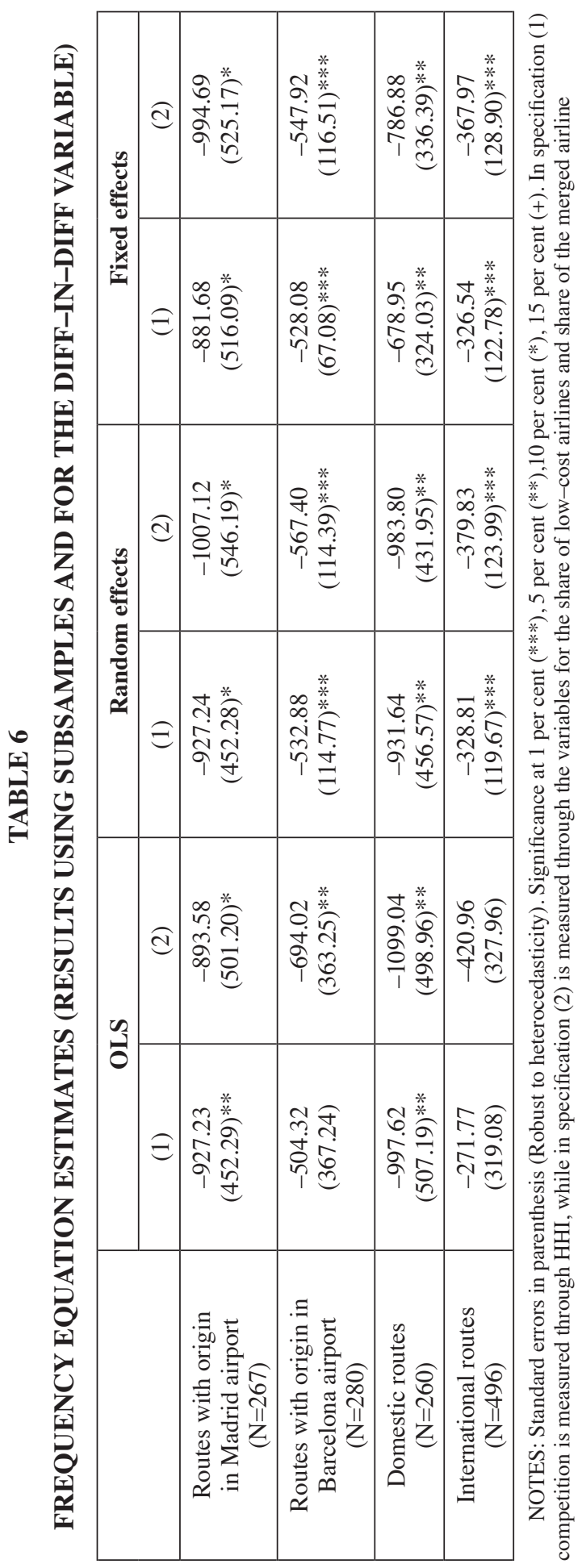


TABLE 7

ELASTICITIES FOR THE DIFF-IN-DIFF VARIABLE EVALUATED AT SAMPLE MEANS

\begin{tabular}{|c|c|c|c|c|c|c|}
\hline & \multicolumn{2}{|c|}{ OLS } & \multicolumn{2}{c|}{ Random effects } & \multicolumn{2}{c|}{ Fixed effects } \\
\cline { 2 - 7 } & $(1)$ & $(2)$ & $(1)$ & $(2)$ & $(1)$ & $(2)$ \\
\hline All routes & -0.43 & -0.54 & -0.47 & -0.49 & -0.44 & -0.47 \\
\hline $\begin{array}{c}\text { Routes with origin in Madrid } \\
\text { airport } \\
\text { (N=267) }\end{array}$ & -0.38 & -0.36 & -0.37 & -0.41 & -0.36 & -0.40 \\
\hline $\begin{array}{c}\text { Routes with origin in } \\
\text { Barcelona airport } \\
\text { (N=280) }\end{array}$ & -0.36 & -0.49 & -0.38 & -0.41 & -0.38 & -0.39 \\
\hline $\begin{array}{c}\text { Domestic routes } \\
\text { (N=260) }\end{array}$ & -0.39 & -0.49 & -0.39 & -0.44 & -0.31 & -0.35 \\
\hline $\begin{array}{c}\text { International routes } \\
\text { (N=496) }\end{array}$ & -0.22 & -0.39 & -0.29 & -0.35 & -0.29 & -0.34 \\
\hline
\end{tabular}

NOTES: Standard errors in parenthesis (Robust to heterocedasticity). Significance at 1 per cent $(* * *), 5$ per cent $(* *), 10$ per cent $(*), 15$ per cent $(+)$. In specification (1) competition is measured through HHI, while in specification (2) is measured through the variables for the share of low-cost airlines and share of the merged airline.

around 4 per cent. Taking the mean values for the whole sample, this would mean that the merger has implied a reduction in about 60 flights per year (a little bit more than one flight per week). Overall, my regressions show a clear fall in route frequencies although the magnitude of the effect is relatively modest.

I do not find consistent differences in the impact of the merger on frequencies in routes with origin either in Madrid or Barcelona airport. Otherwise, the impact of the merger seems to be stronger for domestic than for national routes taking into account that elasticities obtained with the fixed effects estimator are less reliable as they do not capture the effect of time-invariant variables.

It is important to remark here that I find a negative impact of the merger on frequencies even after controlling for several competition indicators and other route attributes. Thus, given the levels of competition, the merger has implied a reduction in the number of flights offered by airlines in the routes affected by the merger.

Indeed, the drop in flight frequencies may be related to the higher concentration or greater share of the merged airline. This airline, which could be less exposed to flights offered by its rivals, could reduce frequencies to save fixed costs and ensure higher load factors for its planes. This drop in frequencies could also be associated with an increased presence of low cost carriers on the routes affected by the merger. However, my regressions take into account all these factors.

It could also be argued that the drop in frequency is due to the fact that, in the postmerger period, the overall economic situation of Spain was worse. However, there is nothing to lead us to think that the routes affected by the merger have suffered most from the crisis than other routes. 
Hence, the most plausible explanation of my results is a more collusive behavior of airlines offering flights in the routes affected by the merger. In the period previous to the merger, competition between Vueling and the other two airlines involved in the merger was very intense. In the period after the merger, competition between Vueling and other airlines operating in the route seems to be softer (regardless the levels of concentration or the share of Vueling in the route).

In this regard, a more collusive behavior could also explain that the impact of the merger has been stronger in domestic routes. Rivals of Vueling in these routes are usually Air Europa or Spanair while airlines like Ryanair, Easyjet are usually operating in the international routes. It could be that big European low-cost airlines were implementing a more aggressive behavior in international routes that were able to do airlines with the bulk of their traffic in the Spanish market.

However, the higher reduction in frequencies in domestic routes could also be explained by a stronger impact of the crisis in such routes as Spain in years 2010 and 2011 was suffering more the crisis than other countries of the European Union that concentrate a high number of destinations in international routes departing from Spanish airports like Germany, United Kingdom, France or Italy.

Overall, the merger may have had a negative impact on passengers in terms of lower flight frequencies. It seems that this negative impact may be explained by a more collusive behavior of airlines offering flights in the affected routes. However, the magnitude of the negative impact is too modest to put into question the decision of the European Commission to approve the merger.

Overall, competition authorities should not be particularly concerned by the dynamics of the Spanish airline market as airport constraints are not currently a major entry barrier and airlines like Ryanair, Easyjet, Air Berlin or Norwegian have an increasing presence in this market. Iberia has a large share of flights in Madrid airport but inter-hub competition and the increasing presence of low-cost airlines and high-speed train services are weakening its dominant position. Vueling has a strong position in Barcelona airport but Ryanair (and other low-cost carriers) are fearsome rivals for this airline.

Intense competition in the airline segment contrasts with the monopoly of AENA in the management of airports with commercial traffic (Bel and Fageda, 2011; Comisión Nacional de los Mercados y la Competencia, 2014). The partial privatization of the airport operator running can aggravate problems in the future in terms of efficiency and incentives arising from the lack of competition between airports to capture traffic of airlines. Hence, competition authorities will likely have to focus on the airport segment of the market in the coming years.

\section{Concluding remarks}

In this paper, I have show that the merger between Iberia, Clickair and Vueling has implied a reduction in the total number of flights offered in routes where two of 
these airlines were operating simultaneously before the merger was made effective. However, the mean estimated impact of this frequency fall is just about a little bit more than one flight per week. Note that in the routes affected by the merger the increase in the concentration index has been small and there has been an increase in the share of low-cost airlines. In this regard, it is also remarkable the decrease in the share of the merged airline. Overall, it does not seem that the merged airline is able to exploit unilaterally its market power after the merger was made effective. At least, this is not a robust explanation for the results of my analysis.

What it seems is that the behavior of airlines operating in the routes affected by the merger is less competitive after than before the merger. In this regard, the intense rivalry between Vueling and Clickair in the period before the merger was not financially sustainable in the longer term at least for the weaker airline. It is not surprising to find some evidence of a more collusive behavior in the period after the merger because a war price was in place in the period before the merger. Thus, the decision of the European Commission to approve the merger seems to be justified. In this regard, note also that the bankruptcy of Vueling was also unavoidable in the context of the aggressive behavior of its rival.

This being said, the ex-post actions of competition authorities (in the case of the airline sector the European Commission) should be complemented by ex-ante actions of national authorities. The transfer of slots of Iberia to Clickair was doubtful from a legal point of view and it could be the case that these two airlines were following a predatory behavior before Vueling was forced to merge with them. In any case, the increased presence of low-cost airlines in a market where capacity constraints at the largest airports are less severe that use to be, seems to guarantee a reasonable intensity in the levels of competition in the coming years.

\section{References}

[1] BEL, G., FAGEDA, X. (2011): «La reforma del modelo de gestión de aeropuertos en España: ¿Gestión conjunta o individual?», Hacienda Pública Española, 196, 109-130

[2] BETTINI, F.A.J., OLIVEIRA, A.V.M (2008): «Airline capacity setting after re-regulation: The Brazilian case in the early 2000s », Journal of Air Transport Management, 14 , 289-292.

[3] BILOTKACH, V. (2011): «Multimarket contact and intensity of competition: evidence form an airline merger», Review of Industrial Organization, 38, 95-115.

[4] BILOTKACH, V., FAGEDA, X., FLORES-FILLOL, R. (2013): «Airline Consolidation and the Distribution of Traffic between Primary and Secondary Hubs», Regional Science and Urban Economics, 43, 951-963.

[5] BILOTKACH, V.; FAGEDA, X., FLORES-FILLOL, R. (2010): «Scheduled service versus personal transportation: The role of distance», Regional Science and Urban Economics, 40, 60-72.

[6] BORENSTEIN, S. (1990): «Airline mergers, airport dominance, and market power», American Economic Review, 80, 400-4. 
[7] BRUECKNER, J.K, LUO. D. (2013): «Measuring Firm Strategic Interaction in ProductQuality Choices: The Case of Airline Flight Frequency», Economics of Transportation, 2, 95-108.

[8] CALZADA, J., FAGEDA, X. (2012): «Public services obligations in the airline market: Lessons from Spain», Review of Industrial Organization, 40, 291-312.

[9] COMISIÓN NACIONAL DE LOS MERCADOS Y LA COMPETENCIA (2014): $E l$ sector aeroportuario en España: Situación actual y recomendaciones de liberalización. Madrid: Comisión Nacional de los Mercados y la Competencia.

[10] DOBSON, P., PIGA, C. (2011): «The impact of mergers on fares structure: Evidence from European low-cost airlines», Economic Enquiry, 51, 1196-1217.

[11] KIM, H., SINGAL, D.V. (1993): «Mergers and market power: evidence from the airline industry», American Economic Review, 83, 549-69.

[12] FAGEDA, X. (2014): «What hurts the dominant airlines at hub airports», Transportation Research E, 70, 177-189.

[13] FAGEDA, X., FERNÁNDEZ-VILLADANGOS, L. (2009): «Triggering competition in the Spanish airline market: the role of airport capacity and low cost carriers», Journal of Air Transport Management, 15, 36-40.

[14] FAGEDA, X., FLORES-FILLOL, R. (2012a): «On the optimal distribution of traffic of network airlines», European Economic Review, 56 (6), 1164-1179.

[15] FAGEDA, X., FLORES-FILLOL, R. (2012b): «Air services on thin routes: Regional versus low-cost airlines», Regional Science and Urban Economics, 42 (4), 702-714.

[16] FAGEDA, X., JIMÉNEZ, J.L, PERDIGUERO, J. (2011): «Price rivalry in airline markets: A successful strategy of a network carrier against a low-cost carrier», Journal of Transport Geography, 19, 658-669

[17] FAGEDA, X., PERDIGUERO, J. (2014): «An empirical analysis of a merger between a network and low-cost airlines», Journal of Transport Economics and Policy, 48, 81-96.

[18] GOLDSBEE, A., SYVERSON, C. (2008): «How do incumbents respond to the threat of entry? Evidence from the major airlines», The Quarterly Journal of Economics, 123(4), 1611-1633.

[19] MORRISON, S.A. (1996): «Airline mergers: A longer view», Journal of Transport Economics and Policy, 30, 237-50.

[20] PAI, V. (2010): «On the factors that affect airline flight frequency and aircraft size», Journal of Air Transport Management, 16, 169-177.

[21] PETERS, C. (2006): «Evaluating the performance of merger simulations: Evidence from the U.S. airline industry», Journal of Law and Economics, 49, 627-49.

[22] RICHARD, O. (2003): «Flight frequency and mergers in airline markets», International Journal of Industrial Organization, 21, 907-922.

[23] SCHIPPER, Y., P. RIETVELD, NIJKAMP, P. (2002): «European airline reform: an empirical welfare analysis», Journal of Transport Economics and Policy, 36, 189-209.

[24] WERDEN, G. J., A. S. JOSKOW, JOHNSON, R.L. (1991): «The effects of mergers on price and output: two case studies from the airline industry», Managerial and Decision Economics, 12, 341-52.

[25] ZHANG, Y., ROUND, D.K (2009): «The effects of China's airline mergers on prices», Journal of Air Transport Management, 15, 315-23.

[26] ZOU, B., HANSEN, M. (2014): «Flight delay impact on airfare and flight frequency: A comprehensive assessment», Transportation Research Part E, 69, 54-4 